Barbosa, LDCS, Silva, MCL \& Sousa, WHP (2020). Perception of the user of the psychosocial care center alcohol and other drugs about nursing care. Research, society and development, 9(7): 1-24, e680974765.

\title{
Percepção do usuário do centro de atenção psicossocial álcool e outras drogas acerca da
} assistência de enfermagem

Perception of the user of the psychosocial care center alcohol and other drugs about nursing care

Percepción del usuario del centro de atención psicosocial alcohol y otras drogas sobre la atención de enfermería

Recebido: 21/05/2020 | Revisado: 21/05/2020 | Aceito: 25/05/2020 | Publicado: 02/06/2020

Liana Dantas da Costa e Silva Barbosa

ORCID: https://orcid.org/0000-0002-8191-102X

Centro Universitário Santo Agostinho, Brasil

E-mail: dantasliana@bol.com.br

Marina Clara Lopes da Silva

ORCID: https://orcid.org/0000-0002-7377-5670

Centro Universitário Santo Agostinho, Brasil

E-mail: mariinaclara69@gmail.com

Washington Henrique Pereira de Sousa

ORCID: https://orcid.org/0000-0002-5512-1710

Centro Universitário Santo Agostinho, Brasil

E-mail: juniork31973@hotmail.com

\section{Resumo}

Partimos do pressuposto que no Estado do Piauí, na Cidade de Teresina, o Centro de Atenção Psicossocial em álcool e outras drogas é um dos dispositivos de apoio para os dependentes químicos, compondo-se por uma equipe interdisciplinar e tendo como propostas a recuperação e reabilitação do usuário que realiza o uso abusivo e nocivo de drogas. O profissional de enfermagem está inserido nessa equipe e assume um compromisso muito importante como agente terapêutico para prestar cuidados e promover ações de suporte aos usuários de drogas e sua família. Essa pesquisa tem como objetivo traçar o perfil sóciodemográfico do usuário, compreender a percepção do dependente químico acerca da assistência de enfermagem prestada no centro psicossocial e as atividades desenvolvidas na instituição. Tratou-se de um estudo 
exploratório descritivo com abordagem qualitativa. Teve como instrumento de análise um formulário semiestruturado, aplicado para quatorze participantes que assinaram o TCLE e o prontuário que foi utilizado para confirmação das informações. Obteve três categorias semânticas a luz de fundamentos teóricos, as ações/procedimentos do enfermeiro ao cliente do CAPSad, acolhimento/receptividade da enfermagem versus engajamento/permanência do usuário no CAPSad e a doação dos enfermeiros além do seu fazer profissional, evidenciando que os entrevistados se encontram satisfeitos com o atendimento de enfermagem proposto ao serviço, indicando um bom relacionamento entre a equipe. Conclui-se que o profissional de enfermagem tem seu papel reconhecido pelos usuários que se favorecem do serviço e desempenha suas atividades de maneira humanizada acarretando benefícios ao tratamento dos adictos.

Palavras-chave: Assistência de enfermagem; Dependência química; Usuário de droga.

\begin{abstract}
We assume that in the state of Piauí, in the city of Teresina, the Psychosocial Care Center on alcohol and other drugs is one of the support devices for chemical addicts, composed by an interdisciplinary team and having as proposals the recovery and rehabilitation of the user who performs the abusive and harmful use of drugs. The nursing professional is part of this team and assumes a very important commitment as a therapeutic agent to provide care and promote support actions to drug users and their families. This research aims to trace the sociodemographic profile of the user, understand the perception of the chemical dependent about the nursing care provided in the psychosocial center and the activities developed in the institution. This was a descriptive exploratory study with a qualitative approach. It had as an instrument of analysis a semi-structured form, applied to fourteen participants who signed the Informed Consent form and the medical records that were used to confirm the information. It obtained three semantic categories in the light of theoretical foundations, the actions/procedures of the nurse to the Capsad client, nursing reception/receptivity versus engagement/permanence of the user in capsad and the donation of nurses in addition to their professional practice, evidencing that the interviewees are satisfied with the nursing care proposed to the service, indicating a good relationship between the team. It is concluded that the nursing professional has its role recognized by the users who favor the service and perform their activities in a humanized way causing benefits to the treatment of addicts.
\end{abstract}

Keywords: Assistance nursing; Drug addiction; Drug user. 


\section{Resumen}

Suponemos que en el estado de Piauí, en la ciudad de Teresina, el Centro de Atención Psicosocial sobre alcohol y otras drogas es uno de los dispositivos de apoyo para los adictos a los químicos, compuesto por un equipo interdisciplinario y teniendo como propuestas la recuperación y rehabilitación del usuario que realiza el uso abusivo y nocivo de las drogas. El profesional de enfermería forma parte de este equipo y asume un compromiso muy importante como agente terapéutico para brindar atención y promover acciones de apoyo a los consumidores de drogas y sus familias. Esta investigación tiene como objetivo rastrear el perfil sociodemográfico del usuario, entender la percepción del dependiente químico sobre la atención de enfermería proporcionada en el centro psicosocial y las actividades desarrolladas en la institución. Se trataba de un estudio exploratorio descriptivo con un enfoque cualitativo. Tenía como instrumento de análisis una forma semiestructurada, aplicada a catorce participantes que firmaron el formulario de Consentimiento Informado y los registros médicos que se utilizaron para confirmar la información. Obtuvo tres categorías semánticas a la luz de las bases teóricas, las acciones/procedimientos de la enfermera al cliente del CAPSad, la recepción/receptividad de enfermería frente a la participación/permanencia del usuario en capsad y la donación de enfermeros además de su práctica profesional, evidenciando que los entrevistados están satisfechos con la atención de enfermería propuesta al servicio, indicando una buena relación entre el equipo. Se concluye que el profesional de enfermería tiene su papel reconocido por los usuarios que favorecen el servicio y realizan sus actividades de forma humanizada causando beneficios al tratamiento de los adictos.

Palabras clave: Asistencia de enfermería; Dependencia química; Usuario de drogas.

\section{Introdução}

Segundo a Organização Mundial de Saúde (OMS, 2017) as drogas são qualquer substância que, introduzida no organismo, interfere no seu funcionamento. Consequentemente, tanto é droga a maconha quanto a aspirina e o antibiótico; tanto o álcool quanto a cocaína; tanto o cigarro quanto LSD; tanto o cafezinho quanto o lança perfume.

A incidência de consumo de drogas tem níveis elevados de acordo com as estatísticas. $\mathrm{O}$ Escritório das Nações Unidas sobre Drogas e Crime (UNODC) publicou o relatório mundial sobre drogas em 2016, dá a estimativa de cerca de 275 milhões de pessoas, isto é, 5,6\% da população mundial entre 15 e 64 anos, usam drogas ilícitas, e de que mais de 25 milhões de usuários de drogas são dependentes químicos e precisam de tratamento para recuperação. 
Segundo o Observatório Brasileiro de Informações (OBID) sobre drogas publicado em 2009, destacou o aumento de internações hospitalares entre 2001 e 2007 sendo 135.585 associadas aos transtornos mentais e comportamentais decorrentes do uso de drogas, onde 69\% estava relacionado ao consumo de álcool, $23 \%$ uso de múltiplas drogas, 5\% uso somente de cocaína. As regiões que apresentaram o maior número de óbitos diretamente associados ao uso foram: Sudeste 44,3\%, Nordeste 27,8\% e Sul 16,3\%, sendo registradas 392 mortes em acidentes associados ao consumo de álcool.

As consequências para a saúde devido ao consumo de álcool e outras drogas variam de acordo com cada organismo, a forma de administração, a quantidade ingerida e qual substância utilizada. As drogas podem causar um estado de dependência, provocando alterações físicas favorecendo o surgimento de outras enfermidades como hipertensão arterial, doenças sexualmente transmissíveis, acidente vascular cerebral, doenças hepáticas e danos neurológicos.

A dependência química é uma doença bastante complexa, determinada por vários fatores. Para compreendê-la, são necessários estudos e abordagens de diversas áreas profissionais. Apesar de ser um problema de saúde, não possui apenas causas orgânicas, pois estão presentes os fatores sociais, familiares e da área psíquica e emocional (Laranjeira, 2006).

O Ministério da Saúde definiu uma política para atenção integral a usuários de álcool e outras drogas (Brasil, 2004). Atualmente, esta política garante a oferta de serviços, tanto aos portadores de transtornos mentais quanto aos indivíduos com problemas que envolvem o álcool e outras drogas (prevenção, promoção e proteção).

Um dos dispositivos de tratamento é o Centro de Atenção Psicossocial em álcool e outras drogas (CAPS ad), no estado do Piauí, em Teresina criado no ano de 2003 obedece ao Projeto Nacional de Políticas contra o uso de drogas vinculado com a Fundação Municipal de Saúde cujo propósito é a recuperação e reabilitação do indivíduo que realiza uso abusivo e nocivo de drogas, encaminhados por outros serviços de apoio do município ou por demanda espontânea, compondo-se de uma equipe interdisciplinar capacitada e especializada.

A interdisciplinaridade é citada como uma estratégia educativa para melhorar o atendimento na instituição tendo uma equipe composta por administrador, assistente administrativo, artesã, assistentes sociais, enfermeiras, psicólogas, técnicas de enfermagem, médicos psiquiátricos e clínicos gerais, agentes de portaria em escala de plantão, auxiliar de cozinha, coordenadora, educador físico, terapeuta ocupacional e equipe de serviços gerais, com o intuito de incentivar as diferentes habilidades para um desenvolvimento favorável ao plano terapêutico. 
A abstinência não pode ser, então, o único objetivo a ser alcançado. Aliás, quando se trata de cuidar de vidas humanas, temos que, necessariamente, lidar com as singularidades, com as diferentes possibilidades e escolhas que são feitas (BRASIL, 2004). A busca por tratamento por parte da família ou do próprio indivíduo é o primeiro passo da necessidade de ajuda.

O cuidado de enfermagem no CAPS segue um horizonte, não se baseando apenas em normas, em rotinas, mas, construindo novos cenários/caminhos, tornando-se o campo mais efetivo a ser conquistado. A convivência diária, o diálogo e a escuta têm sido importantes no cuidado proporcionado pela enfermagem, pois ouvir é um fato fisiológico e escutar requer uma disposição interna de acolher. Devemos aprender a ser, partilhar, comunicar, a ver que o paciente com transtornos mentais é outro de nós (Almeida filho, Moraes \& Peres, 2009).

Diante do exposto, o tratamento deve iniciar por um acolhimento para uma motivação pessoal e uma rede de apoio sólida, depois avaliação multiprofissional para reconhecimento de suas necessidades em busca da reestruturação e reorganização em longo prazo visando à integração no meio familiar e social, e assim propor um projeto terapêutico mais adequado.

\section{Metodologia}

Para coleta de dados foi utilizado um questionário semiestruturado e teve como sujeitos de pesquisa, um grupo de 14 pacientes em tratamento intensivo no CAPSad acima de 18 anos, homens e mulheres em atendimento há mais de quatro meses no período da coleta de dados. Tendo como objeto de estudo, o uso de recurso tecnológico, um aparelho celular, para gravação da voz dos entrevistados, que foram arquivadas em pen-drives e nos e-mails dos pesquisadores, para uma melhor análise posterior das falas e para evitar a perda de informações.

O estudo descritivo visa à identificação, registro e análise das características, fatores ou variáveis que se relacionam com o fenômeno ou processo. Esse tipo de pesquisa pode ser entendido como um estudo de caso onde, após a coleta de dados, é realizada uma análise das relações entre as variáveis para uma posterior determinação dos efeitos resultantes em uma empresa, sistema de produção ou produto (Perovano, 2014).

O método qualitativo é o que se aplica ao estudo da história, das relações, das representações, das crenças, das percepções e das opiniões, produtos das interpretações que os humanos fazem a respeito de como vivem, constroem seus artefatos e a si mesmos, sentem e pensam. As abordagens qualitativas se conformam melhor a investigações de grupos e segmentos delimitados e focalizados, de histórias sociais sob a ótica dos atores, de relações e para análise de discursos e de documentos (Minayo, 2014). 
Neste trabalho trata-se de um estudo exploratório, descritivo, com abordagem qualitativa com um grupo de pacientes do CAPSad, devido à necessidade de verificar a relação com a enfermagem, surgiram várias interpretações dadas pelo grupo trabalhado e dando base para uma análise crítica dos resultados atingidos.

Para Richardson (1989, p. 29), “(...) método de pesquisa significa a escolha de procedimentos sistemáticos para a descrição e explicação de fenômenos". Cada pesquisa realizada deve ser planejada seguindo as normas que acompanham cada estratégia de pesquisa.

Os dados foram coletados a partir de uma entrevista, que teve o apoio de um formulário elaborado e aplicado pelos pesquisadores. Esse instrumento de coleta de dados foi dividido em duas partes, uma para obtenção de dados sócio demográficos constando das variáveis: idade, sexo, tempo de institucionalização, tipo de tratamento e a segunda parte que abrange 4 (quatro) questões abertas, que tratam da percepção do dependente químico acerca da assistência de enfermagem prestada no Centro de Atenção Psicossocial em álcool e outras drogas em Teresina,que serviu de base para a indução da conversa com o participante e para a análise semântica das falas. O prontuário foi utilizado após a autorização do Fiel Depositário para confirmação das informações do perfil sócio demográfico como o tempo na instituição e o tipo de tratamento.

Neste trabalho o desenvolvimento da pesquisa foi fundamental para obtenção de respostas e justificativas e a partir destas, a elaboração de uma análise crítica dos resultados.

\section{Análises e Resultados.}

Os resultados foram analisados em categorias semânticas a luz de fundamentos teóricos.

\subsection{Caracterização do perfil sociodemográfico}

Nessa primeira parte são analisados dados referentes à idade dos respondentes, sexo, a dependência a qual droga, o tempo de tratamento e a sua escolaridade. Verificou-se que a faixa etária ocorre entre 20 a 39 anos de idade e entre 46 a 59 anos de idade, quanto à sexualidade cerca $70 \%$ são do sexo masculino e $30 \%$ do sexo feminino, a dependência ao álcool é relatada por todos os entrevistados e $60 \%$ relataram uso de múltiplas drogas, o tempo de tratamento para todos é o intensivo e a escolaridade é relativamente alta, 50\% ensino superior completo, $40 \%$ ensino médio completo e $10 \%$ ensino fundamental. 


\subsection{Ações/procedimentos do enfermeiro ao cliente do CAPSad}

Nessa categoria pode-se observar que diante do que foi coletado nas entrevistas a atuação do enfermeiro, juntamente com a equipe interdisciplinar, buscam promover a reabilitação psicossocial, com o intuito do cuidado aos usuários de álcool e outras drogas do CAPSad. Propõem assim, ações educativas e procedimentos assistenciais de enfermagem voltados para o seu campo específico de conhecimento, sendo desenvolvidas inúmeras atividades de sua competência como coletas de exames, consulta, realização de palestras e reuniões em grupo, evidenciadas nos depoimentos dos usuários do CAPSad abaixo.

[...] Tem as palestras que são os grupos, que explica um bocado de coisa, coisas que a gente antes não sabia, tem também as consulta que toda semana eles enfermeiros fazem com a gente, eles tiram a nossa pressão, tiram aquele negócio para saber se tem diabetes [...]. (Entrevistado 1)

[...] Tem a reunião em grupo, final de semana passado elas as enfermeiras explicou pra gente umas coisas que às vezes acontecem de um corte, o que a gente tem que fazer os primeiros socorros, caso tenha uma ferida aberta como é que a gente tem que fazer [...]. (Entrevistado 2)

Os enfermeiros dão palestra, ensina a gente em muita coisa, e tira também nossas duvidas lá na hora e depois quando a gente tem vergonha de falar na frente de todo mundo e prefere um particular. (Entrevistado 3)

[...] tem as terapias de grupo que focam muito nas doenças que a gente pode ter, elas focam nas vacinações, as perspectiva de vida nos apoia pra gente não recair, ensina no que e mais provável pra gente não recair (Entrevistado 3)

[...] elas entram com as palestras com uma temática muito boa pedem pra gente encarar e discutir ao mesmo tempo tema consulta de enfermagem, estimula a higiene, uso das medicações. (Entrevistado 6) 
De maneira geral, a maioria dos entrevistados referiu perceber que as atividades propostas pelo profissional de enfermagem melhoram o seu tratamento. Em estudos realizados por Azevedo \& Miranda (2011) tratam sobre o desenvolvimento de habilidades sociais ou culturais é reconhecido como importante atividade que compõem as estratégias de tratamento, muitas delas observadas nas palestras, as quais geram satisfação aos pacientes.

Na pesquisa de Lima et al., (2014) evidenciou que uma das formas de tratar o usuário do serviço apontada pelos profissionais é por meio do programa de redução de danos, onde o objetivo é a prevenção de doenças e a redução de danos sociais, não sendo o fim curativo, mas preventivo. A abstinência nesse caso não é o foco do tratamento, sendo que a meta é propor mudanças com relação ao consumo de drogas, demonstrando ao indivíduo novos hábitos de vida.

Nas falas apresentadas a seguir, os entrevistados relatam a importância de novas temáticas exploradas nas palestras e reuniões em grupo, como doenças sexualmente transmissíveis, doenças acometidas pela ingestão de álcool e outras drogas, e como o corpo sofre alterações significativas por conta do uso.

As atividades que me ajudam aqui são as terapias de grupo que focam muito nas doenças que a gente pode ter, elas focam nas vacinações, as perspectiva de vida nos apoia pra gente não recair, ensina [...]. (Entrevistado 3)

Tem as palestras que elas dão que são bem legais, são bem estruturadas, então é isso elas estão sempre inovando e inovando, elas não ficam só naquele tema repetitivo. (Entrevistado 5)

[...] esclarecem muito sobre as doenças pra nós. Que é as doenças mentais, mais também da saúde em geral, inclusive ela fala sobre vacinas, os efeitos das vacinas, como é que a gente tem que se precaver diante, as doenças sexualmente transmissíveis [...]. (Entrevistado 10)

[...] foi explicado pra gente esses dias pela enfermeira que ofígado e os rins são um dos órgãos mais afetados e eu não sabia, ou seja, eu tava fazendo um mal pro meu corpo que eu não sabia, e agora minha visão ta totalmente diferente [...]. (Entrevistado 11) 
Conforme o autor Kantorski (2008), é de grande importância que os usuários do CAPSad terem domínio em relatar o papel e a função da equipe de enfermagem junto à equipe de saúde, tanto as especificidades existentes no CAPS quanto o trabalho da enfermagem em se inserir em uma prática que vai além dos chamados "recursos tradicionais", como a comunicação terapêutica, relacionamento interpessoal, atendimento individual, administração de palestra e entre outras atividades.

Conforme Milhomem (2012), o profissional de enfermagem ao realizar palestras ou reuniões em grupo contribui na avaliação clínica e/ou orgânica mais completa, proporcionando o levantamento dos problemas vivenciados pelos usuários e permitindo o conhecimento da sua história de saúde. Também é importante o conhecimento para promover um papel de educar, pois o usuário espera da enfermagem orientações sobre suas condições clínicas de saúde.

Conforme o autor supracitado, os profissionais de enfermagem são considerados facilitadores no processo de despertar nos indivíduos do CAPSad o desejo de mudanças em suas vidas, proporcionando nestes o interesse de prevenir possíveis recaídas ou agravos à sua saúde. Sob esse ponto de vista, o enfermeiro é visto como um profissional que colabora para o sucesso do tratamento dos clientes do CAPSad, é reconhecido seu papel e como executam bem suas funções, como evidenciado pelas seguintes falas:

A importância do enfermeiro no meu tratamento é grande, porque eu acho que o CAPSad é muito importante e o enfermeiro aqui é crucial, é algo que não pode deixar de ter [...]. (Entrevistado 3)

[...] a gente aceita que nós precisamos de ajuda, e aceitação não é algo fácil. A gente chega aqui muito pra baixo. Aqui os profissionais levantam nossa autoestima, nos orientam e esse trabalho deles tem feito toda diferença pra mim. (Entrevistado 10)

[...] a gente não pode nem exigir mais dos enfermeiros e dos outros profissionais, porque eles já fazem demais. (Entrevistado 11)

[...] enfermagem aqui tá sempre agindo, nunca tá parada da forma de informação, de medir pressão de se preocupar com a gente, às vezes o psiquiatra passa uma medicação e você não vê o psiquiatra todo dia, mais o enfermeiro tá ali pra esclarecer a dúvida do medicamento, eles nos orienta a não usar medicamento sem prescrição, a importância disso. (Entrevistado 11) 
[...] a importância do enfermeiro aqui é de grande valor porque não é toda hora que a gente tem acesso médicos aqui né. (Entrevistado 14)

Nesse sentindo, Alvares et al., (2012) afirmam que o enfermeiro ao desenvolver as atividades em grupos tem uma percepção da situação real em que os clientes estão vivendo, por meio do conhecimento de dados mais concretos sobre o problema, ajudando-os no enfrentamento da crise vivenciada, tendo como objetivo promover a união e o apoio, aumentando a autoestima e a autoconfiança dos usuários.

A assistência de enfermagem desenvolvida no CAPS é definida por Schrank (2008), onde descreve que participar, estar próximo, fazer em conjunto práticas que são construídas no dia a dia, vivenciadas com o sofrimento psíquico do paciente, geram um vínculo que se reverte em confiança, em caminhos menos sofridos e mais partilhados para inventar novos modelos de atenção em saúde mental. Nas falas apresentadas a seguir, fica evidente que a assistência prestada pela enfermagem no CAPSad é humanizada e promove um vínculo de confiança e afeto entre os envolvidos. Fortalecendo o engajamento do participante ao tratamento, uma vez que eles percebem que os profissionais valorizam e se importam com seu bem-estar e partilham seus problemas na tentativa de ajudá-los.

[...] aqui tem o atendimento individual tudo isso é importante. O enfermeiro nos dá apoio, se preocupam com a gente. Se eles notam algo de estranho eles investigam para saber o que está acontecendo, e isso faz a gente se sentir bem e ver que a gente não está sozinho nessa. (Entrevistado 5)

[...] todo profissional da área da saúde não pode ficar muito mecânico, e aqui as enfermeiras elas não só mede a pressão, como ela apoia, passa um suporte pra gente. (Entrevistado 6)

[...] a enfermagem tá aqui pra cuidar da gente, da nossa saúde, porque lá fora chegou um momento que a gente não ligava pra nada, não ligava pra nossa saúde [...] .(Entrevistado 8) 
Apesar dos usuários perceberem muitos pontos positivos no atendimento prestado no CAPSad, ressaltaram pontos negativos para o funcionamento como a falta de mais profissionais, inclusive enfermeiros, para atender a demanda do centro, mais atividades recreativas para preencher seu tempo e não se sentirem ociosos e insatisfação quanto a infraestrutura, por conta da falta de acessibilidade.

Conforme Ribeiro (2015), um dos fatores que impacta de forma negativa sobre a assistência de enfermagem é a falta de profissionais ou poucos, pois é considerada uma equipe pequena em relação à demanda de procura dos usuários. Apesar desse problema, a equipe trabalha de forma articulada e há cooperação entre todos para a prestação de serviço com qualidade no atendimento. Outro fator que dificulta o serviço da enfermagem nos CAPSad é o tamanho do espaço físico que interfere na qualidade assistencial. Sob esse ponto de vista, alguns sujeitos da pesquisa demonstraram em suas falas, uma insatisfação na quantidade de profissionais presentes no centro e a infraestrutura do prédio onde é prestado o atendimento.

[...] o que falta mesmo aqui no CAPS realmente é mais profissionais, porque às vezes eles têm que resolver algum problema aqui fora do CAPS e fica faltando gente, a demanda é muito grande para poucos profissionais [...]. (Entrevistado 10)

[...] eles só não trabalham melhor por falta de material é lógico né como, por exemplo, o prédio é um prédio pequeno por conta da demanda de tantas pessoas que vem [...]. (Entrevistado10)

[...] na parte da estrutura por conta da demanda que tá imensa estrutura deveria ser melhor. Tipo poderia ter pelo menos o mínimo de mais atividades como uma mesa de ping pong ou algo que não fosse mexer com grandes recursos. (Entrevistado11)

[...] no CAPS seria tipo o prédio como a demanda ta aumentando o prédio poderia ser melhor, tá bom? "Sim tá bom mais poderia ser melhor, ter uma acessibilidade de que usa cadeira de rodas, essa pessoa não tem como ir lá pra cima. (Entrevistado13) 
Nesse discurso, os participantes reconhecem a falta de apoio dos governantes e de mais envolvimento da sociedade e também, das entidades. Portanto, há um desafio para os profissionais que se dão por inteiro para auxiliar na recuperação da saúde.

Diante disso, essa categoria demonstra os cuidados e procedimentos efetivados pelo profissional de enfermagem no CAPSad mostrando que com uma atitude eficaz a assistência prestada tem impacto de forma positiva no tratamento, pois além de tratar os sintomas e os sinais apresentados pelos pacientes, os enfermeiros dão apoio emocional, buscam solucionar o problema de forma humanizada, contribuindo assim para uma melhor adesão do usuário do CAPSad ao tratamento proposto. E que os usuários mostram conhecimento de que há uma grande demanda e pouco recurso para que o este profissional possa ainda desenvolver melhor suas atividades na instituição.

\subsection{Acolhimento/receptividade da enfermagem versus engajamento/permanência do usuário no CAPSad}

Nessa categoria, podemos observar que diante do que foi coletado nas entrevistas, o profissional de enfermagem tem um domínio e sensibilidade no ato de acolher, sendo de grande importância aos usuários do CAPSad, tendo que manter uma postura ética que simpatiza no compromisso de acolhê-los, escutar suas queixas e aconselhar os usuários do serviço, como mostrado nos depoimentos a seguir dos usuários do CAPSad.

[...] ela tem uma parte especial. Ela se identifica muito com nós pacientes. Ela vê quando uma tá mais assim, ela já sabe. (Entrevistado 3)

[...] tudo que os enfermeiros fazem no fim sempre nos ajuda, e o bom é que eles nunca julgam a gente. (Entrevistado 7)

[...] é um lugar que sempre esteve de portas abertas, eu já estou aqui há um bom tempo e eles mesmo com minhas recaídas sempre que eu volto, eu sempre sou bem atendido e eles estão de portas abertas. (Entrevistado 10) 
"Aqui é um centro de apoio muito bom. Os profissionais se dedicam, e mesmo depois de recaídas nossa os profissionais sempre acolhem a gente de braços abertos, e isso é bom [...]. (Entrevistado 11)

[...] por minha parte eu posso dizer que eu sou bem atendido, os enfermeiros me ensinaram a me conhecer. (Entrevistado 12)

Diante dos depoimentos acima fica claro que os profissionais não julgam os usuários do serviço, estando sempre dispostos e desprovidos de julgamentos e preconceitos, permitindo que o paciente se sinta acolhido e que o retorne ao CAPSad, mesmo depois de uma recaída.

Em concordância com Almeida Filho (2009) os CAPSad oferecem um atendimento com ambiente terapêutico-acolhedor, que possa incluir pessoas em situação de crise, muito desestruturadas e que não consigam naquele momento, acompanhar as atividades organizadas na unidade.

Nesse sentindo, trabalhos semelhantes encontraram a mesma relação entre os usuários e o serviço prestado pelo CAPSad, onde se trabalhar com a realidade de cada sujeito é necessário considerar suas crenças, seus valores e sua cultura, colocando a enfermagem no desafio do cuidado interdisciplinar.

Nas falas a seguir, os profissionais de enfermagem e a equipe de saúde se propõem a ter uma atitude que permita receber bem os usuários e escutar de forma adequada e humanizada as suas demandas, inclusive solidarizando-se com o sofrimento, ou seja, expressando empatia, sem julgamentos.

Tudo que as enfermeiras fazem no final, sempre nos ajuda. Além das palestras, eles ajudam no nosso emocional, nos apoiando, dando apoio e incentivando a nunca desistir.(Entrevistado 6)

Eu gosto das enfermeiras, elas entram com as palestras com uma temática muito boa, pedem pra gente encarar e discutir. Ao mesmo tempo, tem a consulta de enfermagem. (Entrevistado 6) 
Research, Society and Development, v. 9, n. 7, e680974765, 2020

(CC BY 4.0) | ISSN 2525-3409 | DOI: http://dx.doi.org/10.33448/rsd-v9i7.4765

“É importante a questão da arte e cultura que estimula aqui no nosso processo, e eles ensinam a gente a pintar e faz com que a gente continue aqui. Pra mim, isso é muito importante. (Entrevistado 13)

Em pesquisa por outra parte, Pinheiro (2006) afirma que há uma desvalorização, por parte do profissional de saúde, na relação com o paciente e esse fato é devida à falta de informação especializada voltada para o entendimento da comunidade, o que considera fundamental para o estabelecimento do vínculo de confiança.

Para Jorge et al., (2011) o acolhimento adequado e a interação são decisivos na relação de cuidado entre o trabalhador de saúde mental e o usuário, pois facilitam a construção da autonomia deste mediante a responsabilização compartilhada e pactuada entre os usuários envolvidos.

Tais considerações reafirmam a ideia de que o acolhimento é uma das diretrizes de maior relevância da Política Nacional de Humanização do SUS, pois implica uma atitude de escuta, aproximação e de bem-estar em relação com o outro. Assim, o acolhimento faz parte das relações que implicam o acesso do usuário ao serviço e de relações que se estabelecem entre trabalhador e usuário de uma forma humanizada, o que significa reconhecer os sujeitos envolvidos como dotados de interesses, desejos e direitos (Brasil, 2018).

Segundo Andrade (2015) o acolhimento é concretizado através de atitudes demonstradas nas relações intersubjetivas diariamente estabelecidas entre os usuários e os profissionais do serviço. Desta forma, as falas a seguir dos usuários possibilitaram apreender que acolhimento não é sinônimo de primeiro atendimento e sim trazem uma concepção ampliada sobre o mesmo, descrevendo a atenção prestada pelo profissional desde a sua porta de entrada até seu retorno após uma recaída.

[...] eu tive recaída da última vez. Eu achei assim que eu tinha decepcionado as enfermeiras, porque elas acreditaram em mim e falaram que eu estava indo tão bem e a gente recair assim, do nada. (Entrevistado 14)

[...] já tem as enfermeiras para nos auxiliar em tudo que a gente precisa e elas sempre estão aqui com a gente. (Entrevistado 7) 
[...] e mesmo depois da recaída, elas me acolheram bem. Eu percebi que eu tinha decepcionado, mas mesmo assim, elas não me destrataram, de braço aberto, porque elas querem que a gente fique sempre pra cima. (Entrevistado 14)

Percebe-se, com isso, que o acolhimento dos profissionais para com os usuários é importante não só na questão do engajamento ao tratamento, mas no retorno do usuário após o processo de recaída, o qual geralmente encontra-se fragilizado e envergonhado com a situação, o que consequentemente, colabora com a manutenção do tratamento.

A questão do acolhimento e do vínculo estabelecido entre os usuários e os profissionais de enfermagem do CAPSad é considerado importante no processo de tratamento da dependência química, no qual podemos entender que o profissional que presta esse acolhimento ao usuário passa a ser o seu Terapeuta Referência (BRASIL, 2010).

Nessa direção, pode-se entender o acolhimento como uma técnica de conversa, um diálogo que deve e pode ser operado por todos os profissionais do serviço, em qualquer momento do atendimento e nos diferentes encontros, e a partir das atitudes realizadas pelo enfermeiro juntamente com a equipe, constrói relações de confiança e vínculos com os pacientes resultando em uma melhor comunicação que repercute em um tratamento eficaz e manutenção da qualidade de vida deste usuário.

\subsection{A doação dos enfermeiros além do seu fazer profissional}

Nessa categoria podemos observar que diante do que foi coletado nas entrevistas, os usuários mencionaram como a enfermagem é uma profissão que exige uma dedicação especial do profissional, onde o cuidar do outro em sua integralidade significa não apenas resolver seus problemas físicos, assim como também identificar todas as suas necessidades e buscar formas de atender.

[...] além de conversar, eles passam pra gente uma segurança que a gente não tem às vezes nem com as pessoas que moram com a gente. A enfermagem é boa aqui por isso entende? (Entrevistado 2) 
[...]Eles nos ajudam até na parte psicológica e isso não é função deles, eu acho né? (Entrevistado 3)

[...] Se não tivesse enfermeiro aqui seria bem complicado, porque além de não ter quem fazer o que eles fazem, a gente sentiria na pele essa falta, né? Porque eles tratam a gente não como paciente e sim, como uma pessoa da família e isso é bom, né? (Entrevistado 4)

[...]Tudo que as enfermeiras fazem no final sempre nos ajuda. Além das palestras, eles ajudam no nosso emocional, nos apoiando, dando apoio e incentivando a nunca desistir. (Entrevistado 6)

[...] Tudo que é feito aqui pelos enfermeiros ajuda a gente. Eles sempre ajudam a gente, até mesmo quando a gente não merece, quando a gente volta de uma recaída, eles nos apoiam em tudo, elas dão pra gente tipo um suporte. (Entrevistado 7)

Nas falas acima os usuários admitem a importância dos enfermeiros no CAPSad e reconhecem como os enfermeiros os tratam com respeito diante suas limitações e seus anseios frente à vida, e também evidenciam que os profissionais demonstram através de uma boa receptividade e um grande engajamento em mantê-los no centro de apoio em álcool e outras drogas, para a sua recuperação social. Os usuários encaram um preconceito da sociedade primitiva frente as suas recaídas, sendo receosos que os profissionais do serviço também pudessem ser intoleráveis, todavia nas falas fica evidenciado que não são assim.

Em pesquisa realizada por Fonseca et al., (2014), no CAPSad de Feira De Santana, em Montes Claros/MG, os usuários reconhecem que os enfermeiros do serviço prestam uma ajuda e um acolhimento que são identificados como estratégias que favorecem no tratamento, onde este cuidado é humanizado, e tem impacto no consumo e na redução de danos causados pelo uso de drogas.

Segundo Kian (2011), o enfermeiro é o profissional que planeja e coordena as atividades referentes ao processo de cuidado da enfermagem, quase sempre exerce o papel de líder da equipe de enfermagem. Além de liderar a equipe, o enfermeiro no desempenho de sua função realiza capacitação para a sua equipe, pois a equipe de enfermagem tem relação direta com o cuidado prestado para o usuário. 
De acordo com International Council of Nurses (2016), ao enfermeiro compete o cuidado autônomo e colaborativo dos indivíduos de todas as idades, famílias, grupos e comunidades, doentes ou saudáveis e em todos ambientes. As atribuições desse profissional vão desde a promoção da saúde e da prevenção de doenças, até o cuidado de povos doentes, de deficientes e de moribundos, além do apoio e da promoção de um ambiente seguro para o paciente, da pesquisa, da participação em dar forma à política de saúde, da gerência de sistemas da saúde e da instrução do cliente. Dessa maneira, o fazer profissional de enfermagem é reconhecido nas falas dos participantes da pesquisa.

[...] se não tivesse enfermeiros aqui, não seria a mesma coisa. Iria ter uma falta grande, como um corpo sem a cabeça. É essencial porque os médicos não tá aqui todo tempo não, mas o enfermeiro sim. (Entrevistado 5)

[...] mais aqui eu vi que eu posso quebrar certas barreiras e realizar meus sonhos, vivendo o hoje, pensando no amanhã e tudo isso eu devo aqui ao CAPSad e aos profissionais que estão com a gente como um todo, né? E principalmente, a doutora que é uma enfermeira que eu admiro muito. (Entrevistado 9)

[...] eu percebo que o papel da enfermagem pelo menos aqui é muito do cuidado mesmo com a gente, de ser uma ponte entre a gente e todos os outros profissionais e eles estão mais próximos da gente e são capazes de nos mostrar o que é certo e é isso basicamente. (Entrevistado 10)

[...] porque às vezes os profissionais se doam muito e acaba até prejudicando a saúde deles. Também, porque trabalhar com a gente é difícil. (Entrevistado 13)

Diante das falas acima, fica claro que o enfermeiro acaba sendo o elo de ligação do usuário do serviço com a equipe multiprofissional, sendo exposto a uma sobrecarga de tarefas, e ao termino do expediente acaba tendo uma jornada de trabalho exaustiva, sendo reconhecido pelos entrevistados que o trabalho do enfermeiro é árduo e que eles estão sujeitos ao adoecimento físico e mental. 
Para Luz et al., (2014) o enfermeiro acaba realizando vários tipos de atividades voltadas para a dependência química, entre elas está a realização da consulta de enfermagem, que contempla uma gama diversa de intervenções, pois compreende as diversas facetas e abordagens adotada pelo profissional para a condução da problemática, abrangendo-se sobre os ideais das teorias de enfermagem e das teorias da psiquiatria, psicologia, antropologia, filosofia e entre outras. O Enfermeiro também atua na realização de educação em saúde, avaliação clínica e manejo de agravos, acompanhamento de terapêuticas farmacológicas, administração de medicamentos, além de atividade de grupos de apoio coletivo e interligação do usuário com os outros integrantes da equipe multidisciplinar.

Conforme o autor Marzano (2006), o cuidado no CAPSad, compete a todos os profissionais e o projeto terapêutico dos pacientes deve ser discutido nas reuniões multiprofissionais, lugar onde as relações da equipe se constroem e se fortalecem, ao se responsabilizar em conjunto, com respeito, intimidade e cumplicidade, pela cogestão do cotidiano. Nas reuniões diárias, a equipe se conhece e aprende a fazer junto, trabalhando as questões que surgem da situação nova, não-hierarquizada, própria desse trabalho interdisciplinar.

[...] Os enfermeiros aqui já fazem até demais eu acho sabe, eles trabalham muito e sempre em prol de ver a gente livre do vício. (Entrevistado 11)

[...] a gente não pode nem exigir mais dos enfermeiros e dos outros profissionais, porque eles já fazem demais (Entrevistado 12)

[...] a importância do enfermeiro aqui é de grande valor porque não é toda hora que a gente tem acesso aos médicos aqui né? Mais aí já tem as enfermeiras para nos auxiliar em tudo que a gente precisa e elas sempre estão aqui com a gente. (Entrevistado 14)

[...] E tudo que é feito aqui pelos os enfermeiros fazem diferença, e é importante né? Então o atendimento é bastante completo, os profissionais eles trabalham muito mais falta mais gente trabalhando aqui pra dar conta da demanda que tá aumentando.(Entrevistado 13) 
Com base nos depoimentos acima Zerbetto (2005) afirma que o profissional de enfermagem consegue olhar para além da dimensão psicológica do sujeito, enxergando essa dimensão inserida num corpo físico e social. Com relação à instituição o enfermeiro, além de organizar seu funcionamento possui facilidade em se envolver em diversas atividades, mesmo as consideradas triviais, pois o que busca é o "encontro" o "estar com o usuário", e, no processo de reabilitação, essa abertura ao que o usuário está solicitando naquele momento e o respeito à expressão de sua subjetividade é que potencializam o cuidado e o vínculo.

Em pesquisa realizada por Mastroianni et al., (2016) também corrobora com o referido estudo que as principais reivindicações ou aspectos que os participantes consideram serem necessários avançar se referem à melhoria nas condições de serviço da própria equipe, pois os participantes percebem a sobrecarga dos profissionais com a demanda do serviço.

Diante disso, percebe-se que o enfermeiro é o profissional que assumi as responsabilidades das ações referentes necessárias na prática da atenção psicossocial. Verifica-se que o enfermeiro, por se envolver nas diversas atividades oferecidas no serviço, é um profissional que possui uma visão sob uma perspectiva mais integral do indivíduo e do funcionamento da instituição.

\section{Conclusão}

Face aos resultados deste estudo oportunizou uma aproximação com a problemática em questão, desde os parâmetros de iniciação da pesquisa, permeada pelos princípios teóricos até a interação com os participantes do estudo, proporcionando momentos de reflexão e descobertas possibilitando a ampliação de conhecimento sobre a temática.

A pesquisa atingiu seu objetivo principal que era compreender a percepção dos dependentes químicos frente a assistência de enfermagem prestada pelos profissionais no serviço CAPSad, onde também foram cumpridos os objetivos específicos que descrevem o perfil sócio demográfico de cada participante da pesquisa, identificar quais as atividades realizadas pelo profissional de enfermagem no CAPSad, analisa a percepção do usuário de drogas referente à assistência da equipe de enfermagem e discuti a percepção do usuário de drogas referente à assistência da equipe de enfermagem.

$\mathrm{Na}$ análise dos resultados identificou-se os pontos positivos e negativos pertinentes da assistência de enfermagem durante o tratamento dos adictos, evidenciando que os entrevistados encontram-se satisfeitos com o atendimento de enfermagem proposto pelo CAPSad, indicando 
um bom relacionamento entre a equipe e um sentimento de realização ao término das atividades como palestras, reuniões em grupo, consulta de enfermagem e coletas de exames no qual os profissionais de enfermagem se propõe a fazer. Outros sujeitos da pesquisa revelaram pontos no serviço do CAPSad negativos como a falta de infraestrutura do prédio, ausência de acessibilidade e a falta de profissionais diante da alta demanda de usuários que procuram o serviço. No entanto, os usuários encontram-se satisfeitos com a assistência prestada pelos profissionais e com o tratamento oferecido, e valorizam a equipe de profissionais, o que parece ser fundamental no tratamento da dependência química, segundo os usuários.

Observou-se também que o vínculo e o acolhimento do profissional de enfermagem para com os usuários colaboram em seu engajamento e manutenção do tratamento e abstinência. Os usuários relataram um maior vínculo afetivo, admiração e gratidão com as enfermeiras, em especial. Assim, o enfermeiro do CAPSad mostra-se atento a todos os pacientes, assumindo ser um profissional acessível às atividades propostas que levam seu fazer profissional além do seu dever e acabam se sobrecarregando, sendo esse excesso de tarefas reconhecido pelos participantes da pesquisa.

O presente estudo revelou que há uma aproximação da percepção dos usuários ao tratamento da dependência de álcool e drogas e o serviço de enfermagem, promovendo uma melhor adesão do usuário ao tratamento, ao se sentirem acolhidos e seguros, desenvolvendo um vínculo que assegura seu engajamento em caso de recaídas, e que mostre que a equipe de enfermagem não favorece a estigmatização ou julgamentos de suas práticas, mas sim o resgaste do autocuidado e sua reabilitação na sociedade.

Dessa maneira, compreende-se que os profissionais da equipe de enfermagem desempenham ações em conjunto e interligadas naquilo que possa ser melhor para o cuidado de cada cliente do CAPSad. Contudo, acredita-se que à medida que houver mais discussões e estudos a respeito do trabalho da enfermagem nesse dispositivo de tratamento, essa compreensão poderá ser ampliada, haja vista que se trata de uma prática indispensável no suporte ao dependente químico.

Sugere-se que durante o processo de formação seja trabalhado com uma maior frequência a temática em discussão, apresentando a teoria e associando-se a prática em campo, despertando interesse em se buscar aprimoramento nesse campo de atuação. E para os profissionais desta área sugere-se ampliar a consulta de enfermagem como forma de assistência. 


\section{Referências}

Almeida Filho, AJ, Moraes AEC \& Peres MAA. (2009). Atuação do enfermeiro nos centros de atenção psicossocial: implicações históricas da enfermagem psiquiátrica. Rev. RENE, Fortaleza, 10(2): 158-65, abr./jun.

Alves A. (2015). Dependência Química Classificação e Diagnóstico, São Paulo. Disponível em: http://www.clinicajorgejaber.com.br/curso/2015/mar_30.pdf.

Alves HMC, Dourado LBR \& Côrtes VNQ. (2013). A influência dos vínculos organizacionais na consolidação dos Centros de Atenção Psicossociais. Rev.Ciência e Saúde Coletiva. 18(10): 2965-75.

Brasil. (2002). Portaria/GM no 336 - de 19 de fevereiro de 2002. Disponível em:http://bvsms.saude.gov.br/bvs/saudelegis/gm/2002/prt0336_19_02_2002.

Brasil. (2015). Centros de atenção psicossocial e unidades de acolhimento como lugares da atenção psicossocial nos territórios: Orientações para elaboração de projetos de construção, reforma e ampliação de CAPS e de UA. Disponível: bvsms.saude.gov.br.

Brasil. (2008). Ministério da Saúde. Secretária de Atenção à Saúde. Núcleo Técnico da Política Nacional de Humanização. Acolhimento nas Práticas de produção de saúde. 2a ed. Brasília (DF): Ministério da Saúde.

Brasil. (2004). Secretaria de Atenção à Saúde. SVC/CN/DST/AIDS. A política do Ministério da Saúde para a atenção integral a usuários de álcool e outras drogas. Brasília. Disponível em: bvsms.saude.gov.br/bvs/publicacoes/pns_alcool_drogas.pdf\&gt.

Brasil. (2015). Legislação e Políticas Públicas sobre Drogas no Brasil. Disponível em: https://www.justica.gov.br/central-de-conteudo/politicas-sobre-drogas.

Bourguignon, LN, Guimarães ES \& Siqueira MM. (2010). A atuação do enfermeiro nos grupos terapêuticos dos CAPS ad do estado do Espírito Santo. Rev:CogitareEnferm. 15(3): 467-73. 
Cavalcante LS et al. (2012). Rede de apoio social ao dependente químico: ecomapa como instrumental na assistência em saúde. Rev Rene. 13(2): 321-31.

Castro MS \& Rosa LC. (2010). Fatores de risco e proteção na prevenção do uso indevido de drogas.Disponível:http://leg.ufpi.br/subsiteFiles/ppged/arquivos/files/VI.encontro.2010.pdf.

Chaim CH, Bandeira KB, Andrade AG. (2015). Fisiopatologia da dependência química. RevMed (São Paulo). out.dez.;94(4): 256-62. Disponível: http://www.revistas.usp.br/.Acesso.

Esperidão E. et al. (2013). A Enfermagem Psiquiátrica, a ABEn e o Departamento Científico de Enfermagem Psiquiátrica e Saúde Mental: avanços e desafios. Rev. bras. enferm., Brasília, 66, set. Disponível em: http://www.scielo.br/.

Esperidão E. (2013). Departamento Científico de Enfermagem Psiquiátrica e Saúde Mental da ABEn. Revista de Enfermagem, Brasília, 66(2).

Mastroianni FC. (2016). Perfil Sóciodemográfico de um CAPSad e sua Funcionalidade Segundo os Usuários. Revista Psicologia e Saúde, 8(2): 3-16, jul./dez.

Faria HP et al. (2009). Processo de trabalho em saúde. NESCON/UFMG. Belo Horizonte: Coopmed.

Ferreira PS et al. (2004). Percebendo as facilidades e dificuldades na implantação de serviços abertos em álcool e drogas. Contexto Enfermagem, 13(2): 209-16, abr.

Fontes A, Figlie NB \& Laranjeira R. (2006). O comportamento de beber entre dependentes de álcool: estudo de seguimento. Revista de psiquiatria clínica, 33(6): 304-12. Disponível em: http://dx.doi.org.

Fonseca, RL etal. (2014). Percepção dos usuários de crack em relação ao uso e tratamento em um Centro de Atenção Psicossocial, álcool e outras drogas. Rev. APS. abr/jun; 17(2): 214-22.

Capsad. (2018). Fundação municipal de saúde. Capsad. Disponível em: http://sus.teresina.pi.gov.br/2018/. 
Horta WA. (1974). Enfermagem: teoria, conceitos, princípios e processo. Revista da Escola de Enfermagem da USP. 7-15.

International Council of Nurses. [citado 2006 maio 05].Disponível em: http://www.icn.ch.

Kantorski LP, Mielke FB \& Teixeira Jr S. (2008). O trabalho do enfermeiro nos centros de atenção psicossocial. Trabalho da Educação de Saúde. mar/jun.

Kian KO, Matsuda LM \& Waidmann MAP. (2011). Compreendendo o cotidiano profissional do enfermeiro-líder. Rev Rene, Fortaleza, 12(4): 72.

Laranjeira R \& Romano M. (2004). Consenso brasileiro sobre políticas públicas do álcool. Rev. Bras. Psiquiatr. [online]. 2004, 26: 68-77. https://doi.org/10.1590/S1516-44462004000500017.

Lima DWC, Silveira LC, Vieira AN, Cunha BMC, Almeida ANS \& Guerreiro EM. (2014).

Referenciais teóricos que norteiam a prática de enfermagem em saúde mental. Escola Anna Nery Revista de Enfermagem. 18(2).

Luz VLE et al. (2014). Ações realizadas pelo enfermeiro em Centros de Atenção Psicossocial. Revista Interdisciplinar, Piaú, 7(4):1-12, out./dez.

Marcolan JF \& Castro RCBR. (2103). Enfermagem em saúde mental e psiquiátrica: desafios e possibilidades do novo contexto do cuidar. Rio de Janeiro: Elsevier.

Martins RV et al. (2012). Ações de saúde mental na região norte do Rio Grande do Sul, brasil. Rev Gaúcha Enferm., 33(1): 11-8.

Mielke BF et al. (2009).O cuidado em saúde mental no CAPS no entendimento dos profissionais: Ciência e Saúde Coletiva, Rio de Janeiro, 14(1): 159-64.

Moraes, F. I. M, et al.,Atuação dos enfermeiros nos centros de atenção psicossocial- Revisão de Literatura. REVISA. 2015; 4(2):155-69. 
Observatório Brasileiro de Informações sobre Drogas - (OBID) (2019). Relatório Brasileiro de Drogas. Disponível em: https://obid.senad.gov.br/dados-informacoes-sobre-drogas/pesquisa-eestatisticas/populacao-geral/relatorio-brasileiro-sobre-drogas.

ONU. (2016). ORGANIZAÇÃO DAS NAÇÕES UNIDAS. Programa para o Controle Internacional de Drogas. Escritório das Nações Unidas Contra Drogas e Crime da ONU UNODC. Brasília, 2016.www.unodc.org/relatorio-mundial-drogas-2016.

ONU. (2019). ORGANIZAÇÃO DAS NAÇÕES UNIDAS. Relatório Mundial de Drogas. Escritório das Nações Unidas Contra Drogas e Crime da ONU - UNODC. Brasília, 2019.Disponivelem: https://www.unodc.org/wdr2019/.Acesso.

Pratta EM \& Santos MA. (2009). O processo saúde-doença e a dependência química: interfaces e evolução. Psicologia: Teoria e Pesquisa, pág. 203-11.

Stefanelli et al. (2011). Enfermagem psiquiátrica em suas dimensões assistenciais. Barueri Manole.

Scivoletto S \& Giusti JS. (2004). Fatores protetores e de risco associados ao uso de drogas na adolescência: Atualização Científica. 2004.

Xavier RT, Monteiro JK. (2013). Tratamento de pacientes usuários de crack e outras drogas nos CAPS AD. Psic. Rev., São Paulo, 22(1): 61-82.

Zerbetto SR \& Pereira MAO. (2005). O trabalho do profissional de nível médio de enfermagem nos novos dispositivos de atenção em saúde mental. Rev: Latino Enferm. 13(1): 112-7.

\section{Porcentagem de contribuição de cada autor no manuscrito}

Liana Dantas da Costa e Silva Barbosa - 33,3\%

Marina Clara Lopes da Silva - 33,3\%

Washington Henrique Pereira de Sousa - 33,3\% 